\title{
ENTRE LA PASIÓN Y EL BAJO AGUÁN: EL ROSTRO VIOLENTO DEL NEOEXTRACTIVISMO PALMERO EN CENTROAMÉRICA
}

\author{
BETWEEN THE PASSION AND LOWER AGUAN RIVERS: THE VIOLENT \\ FACE OF THE NEO-EXTRACTIVIST PALM PRACTICES \\ IN CENTRAL AMERICA
}

Daniel Villafuerte Solís

Recibido: 07/09/2017 - Aceptado: 03/01/2018

\begin{abstract}
Resumen
Las economías de América Latina están experimentando un renovado énfasis en las exportaciones de productos primarios, como lo indica el alto porcentaje de bienes primarios en las exportaciones totales. Esto ha incluido el rápido desarrollo de prácticas que implican la explotación intensiva de los recursos naturales, incluyendo el crecimiento de extensas áreas de cultivos como la soja, la caña de azúcar y la palma aceitera (elaeis guineensis), entre otros. Estas formas de neoextractivismo están teniendo graves impactos, tanto sociales como ambientales. Este artículo se centra en la producción de palma aceitera en la región del Petén de Guatemala y la región del río Bajo Aguán en Honduras, dos casos emblemáticos que generaron complicados conflictos agrarios y socioambientales y que han costado muchas vidas humanas.
\end{abstract}

Palabras clave: Reprimarización, neoextractivismo, palma aceitera, La Pasión, Bajo Aguán.

\begin{abstract}
The economies of Latin America are experiencing renewed emphasis on primary product exports, as indicated by the high percentage of primary goods in total exports. This has included rapid development of practices that involve intensive exploitation of natural resources, including the growth of extensive areas of crops such as soy, sugarcane and palm-oil, among others. These forms of neo-extractivism are having severe impacts, both societal and environmental. This article focuses on palm-oil (elaeis guineensis) production in the Petén region of Guatemala and the Bajo Aguán river region in Honduras, two emblematic cases that generated complicated agrarian and socio-environmental conflicts and that have cost a great many human lives.
\end{abstract}

Keywords: Reprimarization, neoextractivism, palm-oil, La Pasión river región, Bajo Aguán region. 


\section{Introducción}

La expansión de los agrocombustibles constituye una amenaza a la soberanía alimentaria y al derecho a la alimentación de los pueblos, al concentrar la tierra y hacer uso intensivo de los recursos críticos: la tierra y el agua. Un elemento adicional es la contaminación causada por el uso masivo de agroquímicos, la cual termina por generar la expulsión de las poblaciones afectadas; esto se traduce en desplazamientos forzados y procesos de migración interna e internacional.

Como en todo proceso, este modelo productivo tiene defensores y detractores. Unos luchan a favor de la ganancia y otros a favor de la vida. Quienes defienden la ganancia argumentan las bondades del cultivo, el cual genera empleos y materias primas para la industria, así como carburantes, por ejemplo, el biodiésel. Las personas que están en contra cuestionan la concentración de la tierra en pocas manos, el alto consumo de agua y de agroquímicos, así como la contaminación del ambiente y la precariedad laboral.

La relativa estabilidad de los precios, una mayor remuneración frente a otros cultivos, así como el discurso sobre las bondades de la palma aceitera, ha hecho que los campesinos no perciban los efectos ambientales que genera el cultivo. En este sentido, Edelman y León aseguran que "la producción de palma africana se ha convertido en una actividad prestigiosa en el Aguán, ya que evoca imágenes de una mejor vida" (216), un ejemplo en este sentido es la Cooperativa Salamá. ${ }^{1}$ Sin embargo, cada vez se va creando cierta conciencia ecológica, aunque mientras no exista una alternativa mejor para los ingresos de los campesinos el monocultivo seguirá ocupando más tierras. Hoy día, entre quienes fomentan la ampliación de la frontera palmícola destacan el Banco Mundial, el Banco Interamericano de Desarrollo, el Banco Centroamericano de Integración Económica y, desde luego, las empresas productoras, extractoras y comercializadoras. Entre los que rechazan la proliferación del cultivo sobresalen la Organización Fraternal Negra Hondureña (OFRADECH); Plataforma de los Movimientos Sociales y Populares de Honduras; Consejo Cívico de Organizaciones Populares e Indígenas de Honduras (COPINH); Consejo Indígena Maya Chortí de Honduras (CONINMCHH); y la Asociación Nacional de Campesinos de Honduras (ANACH).

Este artículo se propone mostrar el crecimiento que ha tenido el cultivo de la palma en los últimos años y, como consecuencia, algunos de los conflictos derivados. ${ }^{2}$ También interesa identificar los actores involucrados y reflexionar sobre sus implicaciones en la sociedad. Primero se mostrará, a manera de marco general, lo que ocurre en la región centroamericana para luego centrar el análisis en los casos de interés. La exposición se divide en cuatro partes: en primer lugar, se aborda el problema desde una perspectiva teórica; en segundo, se presenta un marco general sobre el cultivo y los actores; en tercer lugar, se analiza el conflicto agrario y ambiental en el Bajo Aguán y La Pasión; y, finalmente, un cuarto apartado analiza las expulsiones. 


\section{Neoliberalismo y neoextractivismo económico}

Centroamérica asume el neoliberalismo económico de manera tardía, si se considera que los primeros experimentos en América Latina comienzan en Chile después del golpe de Estado de 1973 en contra del gobierno del presidente Salvador Allende; pocos años después ocurrirá en Argentina; y en los ochenta en México. Las viejas teorías que fueron enterradas por el keynesianismo resucitaron en el primer país con los llamados Chicago Boys, formados por la escuela de Chicago representada por el economista Milton Friedman.

La tardía entronización de las medidas de ajuste estructural en la región centroamericana, las cuales darán cabida al pleno funcionamiento del nuevo modelo económico, se debe a los conflictos armados en Nicaragua, El Salvador y Guatemala, así como a la inestabilidad política en Honduras. Es hasta inicios de los años noventa del siglo XX que la región comienza una etapa de cambios en las políticas económicas,3 entre estas, la apertura acelerada hacia los mercados externos y los procesos de privatización de sectores clave como las telecomunicaciones y la electricidad.

La apertura comercial y los procesos de desregulación llevan a la crisis del modelo primario-exportador, centrado en productos tradicionales como el algodón, café, banano, carne vacuna y azúcar. Estos no desaparecen, pero pasan a un segundo término como generadores de divisas, cuya fuente ahora son los llamados productos agrícolas no tradicionales, la maquila, minería, turismo y las remesas familiares.

Durante casi tres décadas el neoliberalismo en Centroamérica provocó cambios significativos en las economías, en los ámbitos social y ambiental. Las economías de la región entraron en una etapa de privatización y las empresas extranjeras comenzaron a hacerse presentes en el sector de comercio mediante la compra de supermercados, particularmente, la firma estadounidense Walmart. En la industria textil, aparecieron las maquiladoras estadounidenses y coreanas, lo mismo ocurrió en la maquila de arneses para autos, incluso, en el caso de Costa Rica, en la fabricación de instrumental médico.

México jugó un papel relevante en el proceso de pacificación de la región, después lo haría con la firma de tratados de libre comercio, a partir de la segunda mitad de los noventa del siglo XX. En el 2001, lanza el Plan Puebla-Panamá, el cual allana el camino para la firma de un tratado de libre comercio entre los países de la región y República Dominicana con Estados Unidos, que en la práctica es la versión ampliada de la Iniciativa de la Cuenca del Caribe impulsada por el gobierno de Ronald Reagan en 1982 (Petras; Guerra-Borges), como parte del posicionamiento estratégico de ese país en el marco de los movimientos revolucionarios de esos años en la región.

En este marco, el viejo extractivismo, asociado con una forma de acumulación de capital identificada con el proceso de colonización para extraer riquezas, minería y recursos forestales, principalmente, va dando paso a un modelo neoextractivista, 
de manera que en la actualidad el saqueo no se limita a la extracción de petróleo y minerales, antes bien, incluye la "industria maquiladora", con altos niveles de explotación de la mano de obra y también con una gama de recursos como la pesca y cultivos orientados a la generación de combustibles: caña de azúcar, piñón (jatropha curcas), soya, palma aceitera, entre otros.

Así pues, en los últimos años se ha generado un interesante debate sobre los cambios en las economías latinoamericanas articuladas al modelo neoliberal, en particular se habla de procesos de primarización o reprimarización (Cortés; Gudynas; Cypher; Burchardt; Svampa) donde, de nueva cuenta, los recursos naturales son sometidos a una intensa dinámica de extracción y explotación de gran impacto en el ambiente y en la sociedad, la cual adquiere magnitudes sin parangón, de acuerdo con los procesos extractivos del pasado. Justamente la explotación a gran escala hace que abarque "numerosas relaciones y situaciones como el control territorial, la apropiación de los recursos locales, el desplazamiento de los pobladores del lugar y el acaparamiento de tierras mediante procedimientos conflictivos y violentos" (Cypher 425).

En la mayoría de los casos, se trata de la producción de materias primas, con una lógica de enclave, que tiene como destino principal el mercado internacional. Lo anterior implica la reproducción del esquema de dependencia colonial, ahora en un contexto de economía abierta, desregulada, donde el mercado marca la pauta de la extracción, la cual, en algunos casos, se trata de justificar con un discurso de sustentabilidad, en apariencia científica.

Se produce lo que Maristella Svampa denomina "Consenso de los Commodities"; un despojo de tierras, recursos y territorios, con nuevas formas de dependencia y dominación. Un modelo de acumulación neoextractivista "basado en la sobreexplotación de recursos naturales, en gran medida no renovables" (34). Un neoextractivismo que "no puede reducirse a operaciones vinculadas a materias primas devenidas a escala global, va más allá al involucrar "la dinámica de lo digital y de lo financiero", así como la "extracción de fuerza de trabajo" (Gago y Mezzadra 43).

Svampa sintetiza la idea de extractivismo al indicar que se trata de "un nuevo patrón de acumulación basado en la sobreexplotación de los bienes naturales" (54). Lo anterior se explica por la naturaleza del metabolismo social del capital que "exige para su funcionamiento más materia y energía". El nuevo extractivismo implica "la exportación de bienes primarios a gran escala, entre ellos hidrocarburos, metales y minerales, productos ligados al nuevo paradigma agrario" (54).

En este marco, las grandes empresas nacionales y multinacionales impulsan la búsqueda de nuevas opciones que favorezcan la acumulación de capital, crean nuevos espacios o refuncionalizan los existentes, incluso, en el caso de productos agrícolas, incorporan espacios campesinos a la dinámica del mercado, mediante diversos mecanismos que van desde la asistencia técnica hasta la compra del producto. En esta lógica se produce un fenómeno mundial de acaparamiento de tierras en el sur, "es el nuevo 
terreno de conquista de aventureros y hombres de negocios, de Estados ansiosos por garantizar el abastecimiento de comida a sus ciudadanos y de financieros deseosos de multiplicar sus ganancias" (Liberti 13).

La escala en la que opera el neoextractivismo y la incorporación de los avances tecnológicos son parte de sus características; el crecimiento desenfrenado como elemento primordial de la lógica de este modelo de acumulación hace recordar las palabras de Schumacher cuando afirmaba que "la economía moderna se mueve en una locura de insaciable ambición y se deleita en una orgía de envidia, siendo estos no meramente hechos accidentales, sino las causas últimas de su éxito expansionista" (85). Esta idea proyectada en el presente proporciona la medida de la realidad en la que se vive, en la cual la ciencia y la tecnología se encuentran al servicio de esta carrera que implica envenenar el medio ambiente, o bien, degradar la estructura social.

Todo esto ocurre en un marco más amplio, caracterizado por un capitalismo que considera más importante los recursos explotables que la gente que vive en los territorios dotados de recursos codiciados por el capital, de manera que se produce lo que Sassen denomina expulsiones, un fenómeno que va "más allá de la idea más familiar de desigualdad creciente como forma de aludir a las patologías del capitalismo global de hoy" (11).

Lo anterior tiene una consecuencia esencial en las luchas sociales, pues "los oprimidos en su mayoría han sido expulsados y sobreviven a gran distancia de sus opresores" (21), por ejemplo, los migrantes centroamericanos que sobreviven como clandestinos en Estados Unidos. Un proceso donde "el <opresor > es cada vez un sistema complejo que combina personas, redes y máquinas" (21) y el enemigo no se reduce al gran propietario de la finca, sino que se extiende a una compleja red que incluye el Estado, el capital financiero, la fábrica y el comercio.

En este sentido, se podría decir que, en América Latina, con la reestructuración del capital mundial y la llegada del neoliberalismo, se producen nuevas formas de dependencia, "el proceso de acumulación de capital en la región continúa estando profundamente integrado de manera dependiente al ciclo del capital global" (Féliz 2). En esta nueva fase del capitalismo, siguiendo a Sassen, se produce una reinversión de los mecanismos de acumulación originaria. Hoy, asegura, "es una forma de acumulación primitiva ejecutada a través de complejas operaciones y mucha innovación especializada, desde la lógica de la tercerización hasta los algoritmos de las finanzas" (23).

En 1867, Marx, con respecto a la acumulación originaria, también llamada primitiva, indicó que "la llamada acumulación originaria no es, pues, más que el proceso histórico de disociación entre el productor y los medios de producción” (608). En la interpretación actual de este proceso, Harvey la denomina acumulación por desposesión, asociada a lo que llama "nuevo imperialismo", como una forma de producción del espacio. Este cambio en el término obedece, según el autor, a que llamar acumulación originaria a un proceso que reconoce está en curso parece desacertado. Harvey observa 
que algunos de los rasgos indicados por Marx en la acumulación originaria "se han adecuado y hoy juegan un rol aún más importante que el que habían jugado en el pasado" (113), en particular, apunta al sistema de crédito y al capital financiero, cuyo papel ha sido crucial en la depredación, el fraude y el robo. Además, identifica como rasgos nuevos los acuerdos de propiedad intelectual y, en el caso que ocupa a este trabajo, la depredación de los bienes ambientales globales (tierra, aire y agua) y su creciente mercantilización.

En este marco tiene lugar la expansión del cultivo de la palma aceitera en Centroamérica, ${ }^{4}$ al igual que la soya y la minería a gran escala en varios países de América del Sur. Han contribuido a este proceso la creciente demanda de países emergentes como China, lo cual algunos autores han denominado "Consenso de Beijín", referido de manera genérica como una "nueva configuración de poder internacional que tiene como eje central el ascenso de Beijín" (Bolinaga y Slipak 36) y su contraparte el "Consenso de los Commodities", entre ambos el nexo "es la explotación a gran escala de los recursos naturales" (Bolinaga y Slipak 36).

\section{La expansión del cultivo de la palma aceitera en Centroamérica}

El Movimiento Mundial por los Bosques Tropicales considera que el aceite de palma es una de las industrias de rápido crecimiento y más integradas como agronegocio, lo cual contrasta por ser de las menos estudiadas en términos de sus impactos sociales y ambientales. Esta organización estimó para Guatemala una superficie cultivada con palma de 130000 hectáreas, las cuales representan alrededor del 4 por ciento de la superficie agrícola del país, localizadas en los departamentos de Petén, Izabal, Alta Verapaz, Quiché, Escuintla, Suchitepéquez, Quetzaltenango, San Marcos y Retalhuleu, donde se han producido desplazamientos de comunidades indígenas o expulsiones en la idea de Saskia Sassen. Incluso, va más allá: "cuando una empresa o un gobierno extranjero adquiere una gran extensión de tierra para plantar palma para la producción de biocombustibles, expulsa floras y faunas enteras, pequeños agricultores, instalaciones manufactures rurales y mucho más" (Sassen 94). ${ }^{5}$

La Gremial de Palmicultores de Guatemala (GREPALMA) presenta estimaciones más altas, 146533 hectáreas, donde destacan, por orden de importancia, los departamentos de Petén, con 63558 hectáreas; Izabal, con 24865 hectáreas; y Alta Verapaz, con 20 553. Estos tres departamentos concentran el 74.4 por ciento de la superficie cultivada, le siguen Escuintla con 12445 hectáreas y Quetzaltenango y San Marcos con 9000 hectáreas cada uno. El resto se distribuye en Suchitepéquez, Retalhuleu y Quiché.

Para Honduras se estima una superficie cultivada con palma aceitera de 165000 hectáreas y el número de productores en alrededor de 18 000, de los cuales 16000 son considerados como pequeños, puesto que cultivan entre 50 y 165 hectáreas. El Movimiento 
Mundial por los Bosques Tropicales (11) considera que es a partir de 2009, después del golpe de Estado en contra del gobierno de Manuel Celaya, cuando se consolida la expansión palmera que se acompaña de militarización y violencia contra los campesinos, particularmente en el Valle del Aguán.

En Honduras la expansión de la palma asume la forma más grotesca porque implica formas violentas, con saldos sangrientos. En este sentido, la referida organización considera que, en dicho país, "el monocultivo de palma es uno de los responsables más importantes de la deforestación y la pérdida de territorio por parte de comunidades garífunas y misquitas. Honduras posee una agroindustria agresiva vinculada a poderes políticos, militares y del narcotráfico" (10). Este sello particular para el caso de Honduras retrata los métodos de la acumulación originaria descritos por Marx quien asegura que "fueron cualquier cosa menos idílicos" (608).

Tabla 1

CENTROAMÉRICA: PRODUCCIÓN DE ACEITE DE PALMA Y PALMISTE. ESTIMACIONES PARA 2008. HECTÁREAS Y TONELADAS

\begin{tabular}{ccccccc}
\hline País & $\begin{array}{c}\text { En } \\
\text { producción } \\
\text { (Has) }\end{array}$ & $\begin{array}{c}\text { En } \\
\text { desarrollo } \\
\text { (Has) }\end{array}$ & $\begin{array}{c}\text { Total } \\
(\text { Has })\end{array}$ & $\begin{array}{c}\text { Nuevos } \\
\text { proyectos de } \\
\text { siembra } \\
2008\end{array}$ & $\begin{array}{c}\text { Producción } \\
\text { Aceite crudo } \\
\text { de palma } \\
\text { (miles de } \\
\text { toneladas) }\end{array}$ & $\begin{array}{c}\text { Producción } \\
\text { Aceite crudo } \\
\text { de palmiste } \\
\text { (miles de } \\
\text { toneladas) }\end{array}$ \\
\hline Guatemala & 30000 & 26000 & 56000 & 11000 & 225 & 22 \\
Honduras & 80000 & 15000 & 95000 & 6000 & 250 & 26 \\
Nicaragua & 6000 & 3000 & 9000 & 2000 & 25 & 3 \\
Costa Rica & 55000 & 5000 & 60000 & 2500 & 275 & 26 \\
Total & 171000 & 49000 & 220000 & 21500 & 775 & 77 \\
\hline
\end{tabular}

Fuente: Palmas de Ixcán Limitada. Proyecto de Palma. Guatemala. Subsidiaria de la transnacional estadounidense Green Earth Fuels, LLC. 2008, tomado de Solano, 2009.

Como se puede apreciar en la Tabla 1, en 2008 se registraron 220000 hectáreas cultivadas con palma aceitera en la región, de las cuales cerca de 78 por ciento estaban en producción y se tenían programadas para ese año la siembra de 21500 hectáreas. En el cuadro se puede observar que desde entonces Honduras concentraba 43.2 por ciento de la superficie cultivada, la mayor parte en producción.

En el avance de la frontera palmícola en Honduras confluyen varios factores externos e internos. Entre estos últimos, en materia legal destaca la Ley de Modernización 
Agrícola de 1992 que, a tono con las políticas de "ajuste estructural" de corte neoliberal, introduce consideraciones de orden productivo que violan las disposiciones de la ley agraria (Decreto-Ley 170) que restringe el latifundio. Con esta ley se propicia el mercado de tierras y un movimiento de contrarreforma agraria, de manera que en los dos primeros años de esta ley fueron vendidas 20930 hectáreas en la zona del Aguán, casi 74 por ciento de las tierras que habían sido adjudicadas a los campesinos con la reforma agraria. ${ }^{6}$

En esta misma línea se encuentra el Acuerdo Marco para la Competitividad de la palma aceitera y otras palmáceas, en el cual se considera como medida estratégica, el incremento de la superficie cultivada en 28000 hectáreas "en Atlántida, Cortés, Colón y Yoro, para aprovechar todavía más las ventajas agroecológicas, así como la infraestructura vial, portuaria y de telecomunicaciones existente en esos departamentos" ( $\mathrm{La}$ Gaceta, Diario Oficial de la República de Honduras, 13 de enero de 2006).

Otros factores de la expansión palmícola tienen que ver con las condiciones de rentabilidad económica y con los impactos del huracán Mitch de 1998. En lo primero una racha de buenos precios durante dos décadas que incentivaron la reconversión productiva, sustituyendo parte de las plantaciones bananeras y la ganadería bovina, ${ }^{7}$ y en lo segundo se estima que el Mitch afectó a 15000 hectáreas de palma, que fueron replantadas con el apoyo del gobierno hondureño mediante mecanismos de préstamos a bajo costo, sobre todo para medianos y pequeños productores. El papel del gobierno hondureño ha sido fundamental, para el plan de expansión se contó inicialmente con un crédito del Banco Centroamericano de Integración económica por un monto de 7.2 millones de dólares.

El alza de los precios del aceite de palma actúa como acicate para la expansión del cultivo. En el naciente capitalismo Marx (611) se refería a los "tiempos en los que el dinero es la potencia de las potencias" y justo por ello se produjo en Inglaterra la reconversión de extensas áreas de cultivo en terrenos de pastos para la ganadería ovina. En el caso que nos ocupa, la creciente demanda y de buenos precios del aceite de palma genera la reconversión productiva de áreas ganaderas, bananeras y de granos básicos a tierras para palma aceitera: datos recientes indican que en el mercado de Rotterdam el precio CIF del aceite de palma pasó de 682.9 dólares en 2009 a 755.5 hasta abril de 2017, pasando por una racha de altos precios entre los años 2011 y 2013, con un promedio de 1000 dólares por tonelada (Oil world-sinagap, 2017).

Además de lo señalado, otro elemento que ha estimulado el crecimiento de la frontera palmícola es el establecimiento del Proyecto Mesoamericano de Biocombustibles, liderado por Colombia en el marco del proyecto Mesoamérica que se inicia en 2008 como etapa ampliada del Plan Puebla-Panamá.

En seis años (2008-2014) la frontera palmícola en Centroamérica se había extendido en 63 por ciento, al llegar a casi 358000 hectáreas. Como se puede ver en la Tabla 2, 
el país de mayor crecimiento fue Nicaragua con 122 por ciento; sigue Guatemala, con 114.3 por ciento; en tercer sitio se encuentra Honduras con 58 por ciento; el que menos creció fue Costa Rica.

Tabla 2

SUPERFICIE CULTIVADA CON PALMA ACEITERA EN PAÍSES DE CENTROAMÉRICA, 2014

\begin{tabular}{lcc}
\hline País & $\begin{array}{c}\text { Superficie cultivada } \\
\text { (hectáreas) }\end{array}$ & Participación porcentual \\
\hline Costa Rica & 67562 & 18.90 \\
Guatemala & 120000 & 33.56 \\
Honduras & 150000 & 41.95 \\
Nicaragua & 20000 & 5.59 \\
\hline Total & 357562 & 100.00 \\
\hline
\end{tabular}

Fuente: CONAPALMA (2014).

A pesar de que el mayor crecimiento relativo que registró Nicaragua, el peso más importante lo sigue teniendo Honduras, seguido de Guatemala, que juntos concentraron el 75.5 por de la superficie cultivada en la región. Como se puede apreciar en el Tabla 2, solo Honduras concentraba 42 por ciento. Nicaragua mantiene una tendencia creciente, las estimaciones más recientes son de 30000 hectáreas, lo que significa que en los últimos tres años se han establecido alrededor de 10000 hectáreas (CentralAméricaData.com, 2017). Más de 3000 por año.

En el caso de Guatemala encontramos datos divergentes entre lo que reporta la Encuesta Nacional Agropecuaria (INE, 2015) y CONAPALMA. De acuerdo con la primera fuente, Guatemala contaba en 2014 con 152.7 miles de hectáreas, mientras que la segunda reporta 120000 hectáreas (Tabla 2), una diferencia notable de 33000 hectáreas. Lo interesante es que la Encuesta registra un fuerte crecimiento a partir de 2003, cuando reconoce la existencia de poco más de 31000 hectáreas cultivadas, y para 2013 se había multiplicado por cuatro al contar con 115000 hectáreas, pero lo más sorprendente es que un año después, en 2014, la Encuesta registra casi 153000 hectáreas lo que significa que en un solo año aumentó en 38000 hectáreas.

Además, los datos de la Encuesta revelan que el crecimiento de la superficie cultivada con maíz no se compara con la expansión de la palma. Por ejemplo, en el periodo 2003-2013, mientras la palma se multiplicó por cuatro, el maíz solo creció en 22.6 por ciento; entre 2013 y 2014 la frontera palmícola creció en 33 por ciento, en tanto que el maíz solo fue de 1.8 por ciento. La producción de aceite de palma registró un 
rápido crecimiento al aumentar en 386 por ciento al pasar de 92000 toneladas a 448000 durante el periodo 2005-2014 (FAO, 2017).

De acuerdo con los datos presentados, se puede afirmar que la expansión de la frontera palmícola más importante se ubica en la franja norte de Centroamérica que va desde el departamento de Colón, en Honduras, hasta los departamentos de Petén y Alta Verapaz en Guatemala. El crecimiento que ha tenido el cultivo de la palma aceitera se debe a la conjunción de varios factores, la demanda en el mercado mundial, mejor nivel de rentabilidad frente a otros cultivos, y el apoyo de los gobiernos como en el caso de Honduras que, mediante la Ley para la Modernización y el Desarrollo del sector agrícola de $1992,{ }^{8}$ propició la formación de un mercado de tierras y la concentración en pocas manos. En este escenario, Honduras se convirtió en el líder indiscutible en la producción de aceite en la región, con lo cual se llegó a equiparar con Ecuador, por ejemplo. Entre los años 2000 y 2015, la producción aumentó en casi 200 por ciento, al pasar de 148000 toneladas a 440000 (CommodityBasis, 2017). De hecho, la FAO (2017) reporta para 2014 una producción de 460000 toneladas.

El impuso del cultivo de la palma ocurre en un contexto de demanda mundial de aceite para fines industriales y de búsqueda de combustibles alternos. El capital, en su incesante incursión en nuevos sectores y ramas para su valorización, descubrió en la producción de aceite una oportunidad. En Costa Rica, la disminución de producción bananera por el agotamiento de los suelos y la contaminación con metales pesados generó que desde los años ochenta la United Fruit Company alentara la producción de palma a la zona del Caribe (Movimiento Mundial por los Bosques Tropicales 11).

En los últimos años, se ha observado un crecimiento significativo del cultivo. La Cámara Nacional de Productores de Palma (CANAPALMA) de Costa Rica, refiere que "el cultivo de la palma aceitera recientemente ha crecido de 57000 hectáreas en 2010 a 67562 en 2013 y un estimado de 71000 has para el cierre de 2014. Un factor de éxito es que el $63.7 \%$ de las áreas sembradas están en manos de pequeños productores independientes y cooperativas" (CANAPALMA, 2014).

En Costa Rica, Palma Tica es la empresa líder, que además de poseer enormes superficies de cultivo controla a los productores independientes mediante mecanismos de crédito:

Palma Tica S. A. tiene en su control el procesamiento y la comercialización del 80 por ciento del aceite crudo y estima que del total de hectáreas sembradas de palma aceitera en el país esta misma empresa posee el 40 por ciento de la superficie sembrada, es decir 24800 hectáreas aproximadamente 9 (Movimiento Mundial por los Bosques Tropicales 12).

En Nicaragua entre las empresas que comandan la industria aceitera figuran: Agroindustrial de Oleginosas, Agrosa, E. Chamorro Industrial, S.A., Aceitera Corona y 
Aceitera El Real, "entre las cuatro poseen actualmente entre 13000 y 14000 hectáreas" (CentralAméricaData.com, 2017), un verdadero oligopolio al representar el 70 por ciento de las tierras cultivadas con palma.

Para el caso de Guatemala no existen datos precisos sobre el número y la importancia de las empresas dedicadas al negocio de la palma. Sin embargo, es notaria la presencia de empresas como Palmas del Ixcán, S. A., que opera en Petén con plantaciones de su propiedad y con productores independientes desde 2007. Esta empresa nació como "subsidiaria de la estadounidense Green Earth Fuels (GEF), ${ }^{10}$ una de las principales productoras de agrocombustibles en Estados Unidos con sede en Houston, Texas" (Solano 5). Otras empresas visibles son NaturAceites que tiene muchos años en Guatemala y su influencia se extiende particularmente en Alta Verapaz e Izabal; y Agroaceite S. A., que cuenta con 4817 hectáreas de palma en producción, localizadas principalmente en los departamentos de San Marcos, Quetzaltengo y Retalhuleu, genera más de 1000 empleos directos (RSPO, 2017).

Además de las referidas, se encuentra el grupo INDESA (ahora NaturAceites), que incluye la empresa Palmas de Desarrollo y Palmas del Polochic, S. A., (Solano, 1213), esta última con 5000 hectáreas, estimadas en 2007. Junto con esta última empresa, se encuentra la empresa Olmeca con 30000 hectáreas y Agrocaribe con 7000 hectáreas (Hurtado 346-347). En 2012 un estudio de OXFAM consideró la existencia de 6 grupos empresariales que concentraban una superficie equivalente a la utilizada por más de 66000 productores de subsistencia, estas son: REPSA, Agrocaribe, NaturAceites, Tikindustrias, Hame y Naisa (OXFAM, 2014), aunque se sabe que Repsa es parte de consorcio de industrias Hame.

REPSA (Reforestadora de Palma del Peten, S. A.) es una de las empresas pioneras en la siembra de palma en Guatemala, que inicia a finales de la década de los ochenta en la costa sur, como parte del proceso sustitutivo del cultivo del algodón que entró en crisis por baja de los precios. Esta empresa también es pionera en Petén, inicia en 1999 en Sayaxché; sin precisar el año, este grupo asegura que "el área total de palma de aceite en todo Sayaxché es de alrededor de 48000 hectáreas" (REPSA, s. f.).

La estrategia de estas empresas, además de contar con enormes superficies, incentiva la siembra de palma entre los pequeños y medianos productores independientes a través de la venta de semilla, asistencia técnica, créditos, procesamiento del fruto, es decir se opera una integración y "concentración horizontal" (Hurtado 347). El crecimiento de la frontera palmícola ha sido propiciado por un puñado de empresas que concentran enormes superficies, procesan el producto y dominan el mercado. Estas empresas han sido favorecidas por los gobiernos de la región mediante políticas agrarias y de acceso a los mercados. 


\section{El Bajo Aguán y La Pasión: Conflictos agrarios y socioambientales}

\section{El Bajo Aguán}

El Bajo Aguán se localiza en la porción norte-oriente de honduras, es un espacio ubicado en el departamento norteño de Colón, frente al mar Caribe, y forma parte del extenso Valle de Aguán que tiene una extensión aproximada de 765000 hectáreas. Las tierras eran ocupadas principalmente para la producción de banano, que a finales de los noventa fueron sustituidas por el cultivo de palma aceitera. ${ }^{11}$ Una descripción más precisa de su ubicación la encontramos en el texto de Medina:

El valle del Aguán está formado por el macizo montañoso llamado el Alto Aguán que se desenvuelve desde Yorito hasta el trifinio municipal de Olanchito, Yoro y Jocón; sigue el Medio Aguán que es en esencia el valle de Olanchito y se extiende desde el mencionado trifinio hasta la linea divisoria entre los municipios de Sabá en el departamento de Colón y Olanchito en el departamento de Yoro. Tiene una extensión de 157000 hectáreas. El Bajo Aguán se encuentra totalmente en el departamento de Colón extendiéndose desde el río Sabá o Monga hasta el litoral de atlántico. El área del valle Medio y Bajo es de 608490 hectáreas. La riqueza de sus tierras es igual o mejor que las del valle de Sula (Medina 5).

La zona del Aguán es particularmente compleja porque al conflicto agrario se añade la presencia del narcotráfico, situación que genera inseguridad. Díaz y Zepeda (2012) consideran que "la presencia en gran escala del narcotráfico en la zona del Aguán es una prueba fehaciente de la incapacidad del Estado de Honduras en materia de seguridad para su población" (89).

En 2005 se estimaba una superficie cultivada con palma aceitera de 96229 hectáreas en el país, de las cuales 49000 (51 por ciento) se ubicaban en el Valle del Aguán; en el departamento de Atlántida se contabilizaron 21378 hectáreas (25 por ciento), y el resto se distribuía en los departamentos norteños de Cortés y Yoro. Para el mismo año se consideraba la existencia de 10 empresas mercantiles y cooperativas, así como 4700 productores independientes (Fajardo 14-15).

El Bajo Aguán representa, según Alonzo-Macías (2001), “la capital de la contrarreforma agraria" (1), por cuanto ahí se operó una concentración de la tierra a partir de los cambios en la legislación agraria, en particular con la Ley de Modernización y desarrollo del sector agrícola de 1992, que permitió la pérdida de tierras de los campesinos, logradas con las reformas de los años setenta del siglo XX, y la concentración en manos de pocos terratenientes dedicados al cultivo de la palma.

La zona del Bajo Aguán presenta un conflicto agrario de larga data, pero después del golpe de Estado en junio de 2009 la situación se recrudeció. Se trata de un conflicto agrario por la ocupación de 11000 hectáreas cultivadas con palma aceitera, 
por parte de 5000 campesinos que reclaman la propiedad. Esta situación que ha dejado un saldo de 170 personas muertas, la mayoría campesinos, por enfrentamientos con guardias de seguridad de los terratenientes. “El conflicto del Aguán se ha caracterizado por la estigmatización y criminalización de los campesinos y sus defensores. Ha dado origen a usurpación de tierras, desalojos violentos, amenazas, intimidaciones, desapariciones forzadas y asesinato de campesinos" (Observatorio para la Protección de los Defensores de Derechos Humanos 4).

En 2012 se identificaron 14 grupos de campesinos en el Bajo Aguán; sin embargo, solo dos habían negociado tierras pertenecientes a propietarios privados para que el gobierno comprara y se las entregara, se trata del Movimiento Unificado Campesino del Aguán (MUCA), y del Movimiento Auténtico Renovador Campesino del Aguán (MARCA), que disputan 4600 hectáreas de las fincas San Isidro, propiedad de Miguel Facussé, y La Trinidad y Despertar de René Morales. Facussé es uno de los propietarios más importantes de Honduras, ${ }^{12}$ se estima que posee alrededor de 16000 hectáreas, solo en el Bajo Aguán tiene más de 4000 hectáreas en exceso (Flores, El Socialista Centroamericano).

En medio del conflicto, en 2013 el Ombudsman del Banco Mundial presentó una iniciativa para auditar un proyecto de inversión por 30 millones de dólares financiado por la Corporación Financiera Internacional para el corporativo Dinant para apoyar la expansión de la plantación de palma en el Valle del Aguán. Esta iniciativa ocurrió por la presión de organizaciones y comunidades que argumentan violaciones a los derechos humanos al facilitar el desalojo forzado de campesinos del Valle del Aguán.

Un pronunciamiento firmado por varias organizaciones internacionales refiere que "el conflicto agrario en el Bajo Aguán es el conflicto más grave en América Central en los últimos 15 años, debido a la violencia contra campesinas y campesinos, que se agravó aún más después del golpe de Estado" (APRODEV et al. 2). En junio de 2012, después de 18 años de lucha legal, las fincas San Isidro, La Trinidad y El Despertar fueron restituidas a favor de los miembros del Movimiento Auténtico Reivindicativo del Aguán (MARCA), con el argumento que estas fincas adquiridas por Miguel Facussé y René Morales se hizo de manera ilegal. No obstante, "en agosto de 2012, un grupo de campesinos fue desalojado violentamente por policías y militares" (Observatorio para la Protección de los Defensores de Derechos Humanos 5), y el 22 de septiembre de ese año, Antonio Trejo, el abogado que llevó el caso fue asesinado.

A mediados de agosto de 2013, Roger Pineda, representante de la empresa Dinant informó sobre las invasiones a sus fincas: “Dinant, por ejemplo, tiene todavía tres fincas que siguen invadidas y las cuales no han sido puestas en posesión de la empresa, son 2200 hectáreas adicionales que tienen en poder los grupos campesinos" (Orellana, La Prensa, 2013). En abril de 2014, el presidente Porfirio Lobo (2010-2014) expresó en conferencia de prensa que el conflicto en el Bajo Aguán había dejado de ser un 
conflicto de tierras para convertirse en un asunto de seguridad nacional (El Heraldo, 07 de abril de 2014). En esta oportunidad prometió resolver el conflicto antes de que concluyera su mandato; sin embargo, el conflicto siguió a tres años de estas declaraciones.

A poco más de un mes de las declaraciones del presidente Lobo, la promesa de resolver el conflicto se estaba cumpliendo bajo métodos que nada tienen que ver con un diálogo que el presidente había ofrecido en la conferencia de prensa citada. Otro pronunciamiento firmado por varias organizaciones internacionales en 2014 indicaba el escalamiento del conflicto en el Bajo Aguán:

Según información verificada por las organizaciones locales y nacionales de derechos humanos, este pasado 21 de mayo, en horas de la madrugada, un contingente conformado por 315 miembros del ejército y de la policía y 40 agentes de seguridad privada participaron en el desalojo violento de las fincas Trinidad y El Despertar utilizando bombas lacrimógenas, spray de pimienta y disparos al aire para amedrentar y desplazar a las familias que habitan las fincas. En ambos casos las autoridades se negaron a presentar las órdenes de desalojo, y en el caso de la Trinidad incluso procedieron al desalojo violento sin medir palabra (CIFCA et al. 1).

Más adelante el comunicado indica:

Durante los últimos años, hemos venido monitoriando constantemente la situación de derechos humanos en el valle del Bajo Aguán, inter alia, a través de una misión de verificación internacional de derechos humanos en marzo de 2011, una audiencia temática ante la Comisión Interamericana de Derechos Humanos en Washington, en octubre de 2011, una audiencia pública internacional sobre la situación de los derechos humanos en Tocoa, Colón, el 28 de mayo de 2012, y varias gestiones de apoyo a las diligencias realizadas por el Compliance Advisor Ombusman de la Corporación Financiera del Banco Mundial sobre el caso del Bajo Aguán, en 2013 y 2014. Varias organizaciones firmantes hemos dado seguimiento a la situación de derechos humanos y al conflicto agrario en el Bajo Aguán por más de una década (CIFCA et al. 2).

Por su parte, Dinant, el corporativo de Miguel Facussé, comunicaba el 31 de julio de 2015:

El día de hoy, la fuerza de tarea Xatruch del gobierno de Honduras, de conformidad con la ley y sin la participación de Dinant, desalojó pacíficamente a aproximadamente 30 personas ajenas que habian invadido ilegalmente la finca de palma aceitera "la Occidental" de Dinant, en el Bajo Aguán. Más tarde, una invasión ilegal ocurrió en la finca "San Isidro de Dinant (Dinant).

En el marco de la violencia que desde hace años azota a Honduras, en fechas recientes se vio recrudecida la conflictiva en la región del Bajo Aguán con el asesinato de dos campesinos ocurrido el 18 de octubre de 2016, uno de ellos, José Ángel Flores, presidente del Movimiento Unificado Campesino del Aguán (MUCA). En el lugar del 
crimen fueron encontrados gran cantidad de casquillos de grueso calibre, la Corte Interamericana de Derechos Humanos había pedido medidas de protección, pero las autoridades nunca las ejecutaron (La Prensa, 18 de octubre de 2016).

\section{La Pasión}

La Pasión hace referencia al río del mismo nombre, ubicado en el departamento de Petén, Guatemala, con una extensión aproximada de 345 kilómetros. La Pasión corta el territorio de sur a norte, el sur más poblado y el despoblado norte, un ferry que atraviesa el río conecta el territorio. En él se transportan camionetas con vidrios polarizados de sospechoso origen, pero lo más frecuente a la vista de los lugareños son los camiones cargados con aceite y frutos de palma aceitera: "hay empresas aceiteras que han crecido tanto que donde antes había comunidades hoy se ven planicies de palma aceitera que a la luz del atardecer parecen extensos y tranquilos océanos de color verde" (Hernández, párr. 13). En 2006 se reportó la existencia de 10000 hectáreas sembradas de palma aceitera en la ribera del río La Pasión (Hurtado 249).

Un documento publicado por la organización InsightCrime.org, en julio de 2011, daba cuenta del avance de la palma en Petén:

Ya en el año 2008 estaban sembradas 65 mil hectáreas (unas 1400 caballerías), y la proyección para mediados de esta década que comienza, es de 120 mil hectáreas (2650 caballerías). Empresas como Palmas Ixcán aspiran a controlar 50 mil hectáreas. Pero el Grupo HAMEsiglas de Hugo Antonio Molina Espinoza-por medio de su empresa Olmeca, S. A., es la que tiene mayor concentración de tierra para palma africana (InsightCrime.org 182).

En junio de 2015 se produce el derrame de sustancias contaminantes sobre el río, en el municipio petenero de Sayaxché. Los campesinos afectados denunciaron el hecho, lo que llevó a que una comisión de la Organización Mundial de la Salud (OMS) visitara el lugar. En la inspección de campo, Guadalupe Verdejo de la citada organización, refirió que encontraron erupciones en la piel de los afectados por la contaminación del río. Indicó entre las enfermedades que podrían generar están cáncer, diarreas, infertilidad y abortos, además consideró que no existe control sobre el uso de pesticidas (Pocasangre párr. 4).

Reforestadora de Palma de Petén, S. A. (REPSA), con presencia desde 1999 fue señalada como la responsable. Esta empresa "forma parte del Grupo HAME, un conglomerado de empresas que produce aceite de cocina Olmeca y otros derivados" (Villatoro). Es probable que esto haya llevado a la empresa a hacer explícito su plan de sostenibilidad.

En los 6 puntos de su Plan de Sustentabilidad 2016-2017, la empresa Repsa, exalta el respeto a la ley, el diálogo y la transparencia. En particular, llama la atención 
el punto 2 que dice: "La legislación y los derechos humanos (comunidades locales, sociedad civil, trabajadores y otros grupos de intereses) se respetan plenamente. Se buscará identificar, reducir y gestionar de manera transparente los impactos sociales con comunidades, ONG y otros actores locales" (REPSA, 2017).

Lo interesante del caso del río La Pasión es que permite cuestionar varios de los mitos construidos para justificar la expansión de la palma aceitera en Centroamérica, incluso el contar con la certificación de la ONG Rainforest Alliance ${ }^{13}$, cuyo lema es "a favor de la conservación de la biodiversidad y los medios de vida sustentables". Por definición, las plantaciones, en este caso la palma, es la antítesis de la biodiversidad, se tumba la selva o el bosque para sembrar la planta, que además requiere de grandes cantidades de agua y agroquímicos. Aparte de cuestionar los mitos en torno a la sustentabilidad de las plantaciones, el tema permite, como refiere el Centro de Medios Independientes (2015), "ver con transparencia el modo de actuar de los que tienen acceso al Estado: corrupción y riqueza ilícita como regla básica" (párr. 1).

En pocos días, la contaminación del río había recorrido alrededor de 100 kilómetros, provocando una crisis económica y social al dejar sin trabajo y sin alimento a muchos pobladores que viven de la pesca. El caso no tiene precedentes en el país, el cual fue tipificado como ecocidio por el secretario del Consejo Nacional de Áreas Protegidas (CONAP) (Solano). La cantidad de herbicidas e insecticidas utilizados por hectárea en Centroamérica es impresionante, que son de dos a tres veces en el año por hectárea, a razón dos kilogramos. En el caso de río La Pasión, el peritaje realizado por la Universidad de San Carlos sobre la contaminación dio positivo al considerar que el agente contaminante fue Malation, un producto cuyos efectos son devastadores porque es considerado de alta toxicidad y potencialmente cancerígeno.

Los plaguicidas, insecticidas, herbicidas y fungicidas más usados en la región son los siguientes: Estreptomicina y clorhidrato de oxitetraciclina (Cuprimicin 100 hyper), antibiótico de amplio espectro de acción para el control y prevención de diversas enfermedades causadas por bacterias y micro plasmas; Carbendazim, fungida sistémico de acción preventiva y curativa para el control y prevención de enfermedades provocadas por hongos que dañan a los cultivos, tóxico para los peces y las abejas; Glifosato, herbicida no selectivo de amplio espectro, es ampliamente utilizado en el mundo y el OMS ha considerado como probablemente cancerígeno para el ser humano; Cobra 1.8 EC, insecticida-acaricida; Ridomil, fungicida sistemático, la empresa Syngenta recomienda que durante el manejo del producto debe evitarse la contaminación de suelos, ríos, lagunas, arroyos, presas, canales o depósitos de agua; Rhodax WP 70, poderoso fungicida altamente tóxico para el ser humano y el ambiente; Amistar 50 WG, fungicida clasificado como pesticida de riesgo reducido, aunque se recomienda usar siempre equipo de protección.

El herbicida más usado en el cultivo de la palma aceitera es el Glifosato ${ }^{14}$, aunque al principio fue considerado como un producto de baja toxicidad en "2015, la 
Agencia Internacional de Investigación en Cáncer lo reclasificó como 'probable cancerígeno en humanos'; también liga con daño en cromosomas y en el ADN de células humanas" (Ramírez, Bravo y Herrera 61). No obstante, en 2016 la FAO y la OMS concluyeron que "es poco probable que el glifosato suponga un riesgo cancerígeno para los seres humanos a través de la dieta" (FAO-OMS, 2016).

\section{El cultivo de la palma y las expulsiones}

El cultivo de la palma guarda una correlación positiva con las expulsiones, es decir desplazamientos forzados y migración al interior del país y a los Estados Unidos de Norte América. En el caso de Honduras, un análisis realizado con una base de datos de migrantes deportados vía aérea revela un alto porcentaje de personas de origen de los departamentos de Cortés, Yoro, Colón y Atlántida (ACNUR 25), que es justamente la zona de expansión del cultivo de la palma. También hay una coincidencia con la Encuesta Semestral de Remesas Familiares (Banco Central de Honduras, 2016), al indicar los mismos departamentos como los más importantes que visitaron los migrantes durante su estadía en el país, y aquí de nueva cuenta es Cortés el más alto.

Otro dato interesante es que, en 2012, en estos departamentos se registró las tasas más altas de homicidios por cada 100000 habitantes, destacando Atlántida con 129.4, Cortés con 128.9 por ciento, Yoro con 93.4 y Colón con 90.3 (ACNUR 27). Cifras que están por arriba del promedio nacional que para ese año alcanzó 85.5 por 100000 habitantes. Es claro que la alarmante criminalidad no se explica solo por el conflicto agrario y la expansión del cultivo de la palma. Aquí confluyen otros factores, entre los que destaca la presencia del narcotráfico pues este espacio es una de las rutas más importantes por donde transita la droga a Estados Unidos.

En lo que respecta a Petén, en Guatemala, existe una problemática agraria muy compleja de muchos años atrás, asociada al proceso de colonización, y en años recientes a la conjunción de intereses del gobierno, de la compañía petrolera Perenco que ha financiado el establecimiento de campamentos militares, de los ganaderos y madereros, así como de los grupos criminales dedicadas al narcotráfico. Todo esto ha provocado expulsiones: en 200828 comunidades enteras desaparecieron en el departamento de Petén y 2500 familias emigraron por presión de las empresas o del crimen organizado (Brigadas Internacionales de Paz 37).

El territorio petenero es complejo, un campo de batalla que comenzó con la colonización de este vasto territorio de 35835 kilómetros cuadrados donde pueden caber Belice y El Salvador juntos, los actores los describe Oswaldo J. Hernández de manera elocuente:

Hay narcotraficantes violentos, como los Zetas, que han sido los últimos en llegar. Pero aqui, los primeros dueños de este territorio, finqueros y ganaderos, llegaron hace más de 50 años; 
indigenas q'eqchies y petroleros, hace más de 25; y narcotraficantes tradicionales y empresarios de palma africana, que aparecieron (como parte de los propietarios) hace más de una década (Hernández 10).

El autor referido comenta que parte de la historia de este extenso territorio son "los desplazamientos, la extensa compra y arrendamientos de propiedades por parte de la palma aceitera, los q'eqchíes que venden cientos de parcelas y el territorio que ha sido marcado por el crimen organizado" (párr. 23).

La palma africana ya es un cultivo extensivo en Sayaxché y están contabilizadas 26 comunidades que han vendido su tierra para este proyecto que tiene una procesadora junto al Rí La Pasión y que se está analizando para ver su impacto medio ambiental. De igual manera está el interés de los azucareros (InsightCrime.org 183-184).

Petén es tierra de migrantes y aunque no figuran dentro los de mayor movilidad humana, en comparación con otros departamentos fronterizos como San Marcos y Huehuetenango, se registra un flujo importante, además que en la última década se posicionó como un territorio de tránsito de migrantes provenientes de Honduras y otros países de Sudamérica. Aquí las expulsiones provienen principalmente de la ocupación de tierras por todos los métodos posibles e imaginables, desde los más sutiles hasta los más violentos.

Por lo menos dos masacres han ocurrido en los últimos años, uno de ellos ocurrió el 15 de mayo de 2011 en la finca Los Cocos, La Libertad, donde fueron asesinados 27 campesinos. La respuesta del presidente Álvaro Colom fue la implementación del Estado de Sitio por 30 días. El artículo 2 de este decreto señala:

El Estado de Sitio se decreta en virtud que durante los últimos días se han suscitado en el Departamento de Petén, una serie de hechos graves que ponen en peligro el orden constitucional, la gobernabilidad y la seguridad del Estado, afectando a personas y familias, poniendo en riesgo la vida, la libertad, la justicia, la seguridad, la paz y el desarrollo integral de las personas (Presidencia de la República).

Otro hecho tuvo lugar en San Luis, Petén, el 9 de febrero de 2014, en este acto 9 personas fueron masacradas con armas de asalto, ocho miembros de una familia y un hombre no identificado, entre las víctimas se encontraban una niña de tres meses y otra de 5 años.

Desde el año 2000 se sabe de la venta de parcelas en Sayaxché, un municipio que comparte el río La Pasión, donde se habla de la "extinción de comunidades ahogadas por el mar de la palma" (Hernández, párr. 36). La causa es la venta de tierras, pero también la escasa demanda de mano de obra que genera la palma aceitera. Esta es 
voraz, camina rápido, expulsa y extingue comunidades, recuerda Hernández, "solo en Sayaxché, se pasó de tener 465 hectáreas sembradas de palma en el año 2000, a 14 mil 986 en 2006 y a 28 mil 554 en el año 2010" (párr. 48).

El municipio de Sayaxché constituye un centro de resonancia de lo que ocurre con la palma aceitera, ahí han desaparecido comunidades y es donde operan las empresas Reforestadora de Palma S. A. (REPSA), Tikindustrias S. A., Nacional Agroindustrial S. A. (NAISA) y Palmas del Ixcán. Además del conflicto ambiental por la contaminación del río La Pasión, se han registrado manifestaciones de inconformidad laboral con las empresas referidas. En este sentido, un comunicado del Consejo Nacional de Desplazados de Guatemala (CONDEG) informa: "el 8 de mayo de 2012, desde las 4 de la madrugada, se realizaron bloqueos en 6 puntos por más de 12 mil personas de las comunidades del municipio de Sayaxché Petén, participando la mayoría de las microrregiones del municipio" (CONDEG párr. 9).

Sin embargo, el poder de las empresas está por encima de las disposiciones ambientales, dos años y medio después de este bloqueo, en octubre de 2014, se volvieron plantear la solución a los mismos problemas: "bajos salarios, falta de contratos, negación a acceso al Seguro Social, exposición a agroquímicos tóxicos, despidos injustificados, y otros" (Vélez párr. 38).

\section{Conclusiones}

Los casos estudiados ponen de manifiesto las principales contradicciones y consecuencias que se derivan del cultivo de la palma aceitera en Centroamérica. En torno a este cultivo se identifican poderosas familias de Guatemala y Honduras que concentran tierras, producción y procesadoras de aceite, vinculadas a los mercados nacionales e internacionales. También permite ver la relación entre los grupos empresariales y el Estado, que han venido alentando la producción, favoreciendo su expansión a través de estímulos crediticios y fiscales, omisión de responsabilidades en el cuidado del ambiente y protegiendo la concentración de tierras en pocas manos.

A principios de 2016 fueron registrados por la Secretaría de Asuntos Agrarios de Guatemala 1476 conflictos, principalmente en la llamada Franja Transversal del Norte, justo donde la palma se ha extendido, "los más afectados fueron los departamentos de Huehuetenango con 275 casos, Petén con 199, Alta Verapaz con 191, Quiché con 170 e Izabal con 145" (Zepeda 18). El extractivismo palmícola ha contribuido a estos conflictos por la tendencia a la concentración de la tierra y por el modelo productivo que genera contaminación ambiental.

El caso del río La Pasión aporta evidencias entorno a la impunidad con la que actúan las empresas. A un año de ocurrido la mortandad de peces, que afectó alrededor de 185 kilómetros y perjudicó directamente a 117 familias, las investigaciones no han tenido resultados, el representante del Centro Acción Legal, Ambiental y Social de 
Guatemala (Calas) considera que la Sala de Apelaciones de Petén "ha emitido resoluciones contradictorias, desatinadas e ilegales" (Sánchez y Obando). Esa instancia otorgó varios amparos a favor de REPSA, empresa que pertenece al poderoso grupo Agroindustrias HAME de las familias Molina Espinosa y Molina Botrán. Este grupo controla alrededor del 50 por ciento de la producción de palma y de aceite en Guatemala.

En el caso del Bajo Aguán, Honduras, están involucradas las familias de Reynaldo Morales y Miguel Facussé. Miguel (conocido como el "tío Mike"), fue la cabeza más visible como presidente de la Corporación Dinant propietaria de fincas y fábricas. Miguel Facussé fue tío del presidente Carlos Roberto flores que gobernó Honduras durante el periodo 1998-2002. Fungió como asesor principal en materia económica del presidente Roberto Suazo Córdova (1982-1986) y fue considerado uno de los tres hombres más poderosos de Honduras; además de su fortuna dineraria era propietario de 16000 hectáreas de tierra. Las muertes atribuidas al conflicto agrario en el Bajo Aguán, que involucraron directamente a Miguel Facussé permanecen impunes. Hasta ahora no hay resultados del equipo formado en febrero de 2014 por militares, policías y fiscales para investigar más de 170 asesinatos.

\section{Notas}

1 La Cooperativa de Producción Agropecuaria de Campesinos, Limitada, está conformada por 66 miembros con una superficie cultivada con palma de 1500 hectáreas, posee una planta extractora en la que se procesa 86813 toneladas de fruta al año, con una producción de 19359 toneladas de palma crudo, el que se vende a Hondupalma (RSPO, 2017).

Aunque no existen suficientes evidencias empíricas para establecer un vínculo fuerte entre palma y violencia hay numerosos hechos documentados sobre esta relación, aparte de los analizados en este artículo, están los casos documentados en Colombia (Ocampo, 2009; García, 2013) y otras partes del mundo (GRAIN, 2016; Zuckerman, 2016), que muestran los graves problemas que generan la expansión de la palma aceitera.

Ciertamente, Costa Rica fue el primer país de la región en adherirse a las políticas del Banco Mundial y del Fondo Monetario Internacional. En 1985 se aprueba el primer Programa de Ajuste Estructural, que significó la "re-estructuración del aparato productivo; la diversificación de la producción industrial y la promoción de las exportaciones no tradicionales a mercados fuera de la región centroamericana" (Robles Rivera 99).

Justamente, Sara Mingorría (2016) en su análisis sobre Guatemala hace referencia a la demanda de los denominados cultivos flexibles, como la palma aceitera y la caña de azúcar, en tanto que tienen variados usos: alimento, agrocombustible, materia prima para elaborar productos industriales. A esto hay que agregar que "las multinacionales agroalimentarias y los grandes supermercados están en plena expansión especialmente en África, Asia y América Latina fomentando el consumo de alimentos procesados y empacados con base en aceite de palma" (GRAIN, 2016).

Malasia e Indonesia representan el modelo de las grandes plantaciones de palma aceitera en el mundo. No es el caso de África donde todavía predomina la producción campesina. Sin embargo, "en los últimos quince años, firmas extranjeras lograron más de 60 contratos por 
casi 4 millones de hectáreas, para establecer plantaciones de palma aceitera en África. Los acaparamientos de tierra ya suscitan violentos conflictos en varios países" (GRAIN, 2016). GRAIN agrega algo en lo que estamos de acuerdo: "este desarrollo brutal de aceite de palma no se reduce a un problema de tierras. Es una lucha global, centrada en los sistemas alimentarios y los modelos de desarrollo" (GRAIN, 2016).

Debemos considerar que, de acuerdo al Censo Agropecuario de 1993, se registra la existencia de una estructura agraria polarizada donde de un total de 317111 predios, que abarcan una superficie de 3331324 hectáreas, el grupo de menos de una hectárea y hasta 5 concentraron 71.78 por ciento de los predios pero solo tenían el 11.52 por ciento de la superficie; en el otro extremo, los predios de 100 y más de 200 hectáreas representaron solo 1.63 de total pero concentraron 39.62 por ciento de la tierra.

En dos décadas y media (1966-1992), la superficie con pastos naturales creció en 108.4 por ciento, al pasar de 428959 hectáreas a 894012 hectáreas. A esta cifra hay que sumar 468748 hectáreas de pastos cultivados, con lo que tenemos una idea muy clara del predominio de la superficie para la explotación ganadera.

Publicada en La Gaceta Diario Oficial de la República de Honduras, N. 26 713, de fecha 6 de abril de 1992.

Si nos atenemos a las cifras de la Tabla 2, el porcentaje estaría en torno al 36 por ciento, lo cual no deja de ser una cifra muy alta.

Esta empresa se retiró en 2011 y quedó en manos de accionistas nacionales.

Aunque los antecedentes del cultivo de la palma aceitera se remontan a inicios de los años treinta del siglo XX, -en forma experimental con semillas traídas por la United Brans de lugares tan lejanos como Sumatra, Java, Sierra Leona, Congo Belga y de los Estados Federados de Malasia-, las primeras plantaciones comerciales se establecieron en 1936 y 1938. Sin embargo, su auge data de los primeros años de la década de los setenta, y solo en los 90 alcanzan tasas de crecimiento superior al 7 por ciento anual, bajo el impulso de las grandes empresas, entre otras Jaremar, Dinant y Aceydesa (Techno Serve).

Miguel Facussé murió el 23 de junio de 2015, a los 91 años. En una entrevista para la revista Forbes, meses antes de su muerte, habló de su trabajo al frente del corporativo DINANT, una de las pocas empresas que integran toda la cadena de valor de la palma, para impulsar el crecimiento de la palma aceitera fuera de Centroamérica, refirió: "por lo menos nosotros creemos que en el crecimiento está el secreto del éxito, y lo buscamos. Por eso apuntamos ahora a República Dominicana y no descartamos Colombia" (Agüero y Naum párr. 33).

En la certificación también participa de manera destacada la Roundtable on Sustainable Palm Oil (RSPO), proceso legitimado por el Fondo Mundial para la Naturaleza (WWF, por sus siglas en inglés). “La RSPO fue creada en el año 2004 y para el 2012 la red aducía poseer más de mil afiliados provenientes de 50 países, integrado por productores, procesadores, consumidores, distribuidores, banqueros y organizaciones ambientalistas y sociales" (OFRANEH párr. 1). Entre las empresas hondureñas afiliadas a la RSPO se encuentran las siguientes: Aceites y Derivados, Sociedad Anónima (ACEYDESA); Agroindustria de Palma Real, S. A de C.V; Coapalma Ecara; Cooperativa de Producción Agropecuaria de Campesinos Salamá, Limitada; Industrias Aceiteras del Caribe de Honduras (Honducaribe-Ecara); Corporación Industrial de Sula, S. A. (COINSU); Hondupalma; Palmeros de Aguán, S.A. (Palmasa); Unión de Palmeros del Litoral Atlántico (Umpala) (RSPO). 
En el año 2013, Costa Rica importó 1714.4 toneladas de Glifosato y se estima que el mayor consumo es para la palma aceitera, que es de 24.9 por ciento (Ramírez, Bravo y Herrera 66), esto es 428 toneladas, situación que cuestiona el cultivo de la palma en la región. Si consideramos que la superficie cultivada de palma en Centroamérica ronda las 400000 hectáreas y si la dosis recomendada es de 2.5 litros por hectárea el consumo de este producto será de 1 millón de litros; sin embargo, es necesario considerar que es frecuente más de una aplicación por la tendencia a la resistencia del producto.

\section{Bibliografía}

ACNUR. “Caracterización de la población hondureña retornada con necesidades de protección”. Tegucigalpa, Honduras. 2015.

Agüero, Luisa y Naum, Uriel. "Miguel Facussé, el genio de las marcas en Centroamérica". Forbes Staff. 3 de noviembre de 2014. Recuperado de https://www.forbes.com.mx/ miguel-facusse-el-genio-de-las-marcas-en-centroamerica/

Alonzo-Macías, Miguel. La capital de la Contrarreforma Agraria: El Bajo Aguán de Honduras. Tegucigalpa, Honduras: Editorial Guaymuras. 2001.

APRODEV, et al. "Pronunciamiento Internacional". Bajo Aguán, Honduras. 01 de marzo, 2013. Recuperado de http://www.fian.org/fileadmin/media/publications_2015/ Pronunciamiento_Internacional_CAO_-_Bajo_Aguan_01-03-201.pdf

Banco Central de Honduras. "Resultados Encuesta Semestral de Remesas Familiares, Subgerencia de Estudios Económicos". Enero, 2016. Recuperado de http://www.bch. hn/download/remesas_familiares/remesas_familiares_012016.pdf

Bolinaga, Luciano y Slipak, Ariel. “El Consenso de Beijín y la reprimarización productiva en América Latina: El caso argentino". Revista Problemas del Desarrollo, 183(46). 2015: 33-58.

Brigadas Internacionales de Paz. "Petén: las comunidades invisibles". Boletín especial. Proyecto, Guatemala. Abriendo espacio para la paz. Guatemala. 2012. Recuperado de http:// www.peacebrigades.org/fileadmin/user_files/projects/guatemala/files/spanish/ PBI_Guatemala_Boletin_especial_2012_Peten.pdf

Burchardt, Hans-Jürgen. "Neoextractivismo y desarrollo: fortalezas y límites". Poscrecimiento y buen vivir. Coord. Endara, Gustavo. Ecuador. Friedrich-EbertStiftung (FES-ILDIS). 2014.

CANAPALMA. "Información del cultivo de palma en Costa Rica". 12 de diciembre, 2014. Recuperado de http://www.canapalma.cr/images/CANAPALMA_Informacion_ Cultivo_de_PA_en_Costa_Rica_12Dic2014.pdf

CentralAméricaData.com. “Nicaragua: anuncian inversión en palma aceitera”. 17 de febrero, 2017. Recuperado de http://www.centralamericadata.com/es/article/home/ Nicaragua_Anuncian_inversin_en_palma_aceitera

Centro de Medios Independientes. "Palma Africana en Sayaxché: millonario negocio sin garantías sociales, ambientales y laborales". 29 de junio, 2015. Recuperado de https:// cmiguate.org/palma-africana-en-sayaxche-millonario-negocio-sin-garantias-sociales-ambientales-y-laborales/

CIFCA, et al. "Pronunciamiento internacional". 28 de mayo, 2014. Bajo Aguán, Honduras. Recuperado de http://www.fian.org/fileadmin/media/publications_2015/Pronunciamiento_ Internacional_Bajo_Aguan_28-05-2014.pdf 
CommodityBasis. "Palm Oil Producers". 2017. Recuperado de https://www.commoditybasis. com/palmoil_prices

CONDEG. "Comunicado". Guatemala. 15 de mayo, 2012. Recuperado de http://www.cooperaccio.org/wp-content/uploads/2012/05/pet\%C3\%A9n.pdf

Cortés, Alexis. La Reprimarización del Modelo de Desarrollo Chileno. Oikos, 11(1), 2012: 63-86.

Cypher, James. Neoextractivismo y primarización: términos de intercambio en América del Sur. En Democracia, financiarización y neoextractivismo ante los desafios de la industrialización y el mercado de trabajo. Coord. Girón, Alicia. México. Colección de libros de la Revista Problemas del Desarrollo, Universidad Autónoma de México. 2014.

Díaz, Ruy y Zepeda, German. “Diagnóstico de la problemática de derechos humanos en el Bajo Aguán". Agencia Católica Irlandesa para el Desarrollo (Trocaire). San Pedro Sula, Honduras. 2012. Recuperado de https://issuu.com/inggallardo/docs/diagnostico_de_la_problematica_en_e

Dinant. "Comunicado de corporación Dinant sobre invasiones de fincas", 31 de julio, 2015. Tegucigalpa, Honduras. Recuperado de http://www.dinant.com/index.php/es/salade-prensa/comunicados/337-comunicado-de-corporaci\%C3\%B3n-dinant-sobre-invasiones-de-fincas

Edelman, Marc y León, Andrés. Ciclos de acaparamiento de tierras en Centroamérica: Un argumento a favor de historizar y un estudio de caso del Bajo Aguán, Honduras. Anuario de Estudios Centroamericanos, 40, 2014: 195-228.

El Heraldo. "Conflicto en el Bajo Aguán es un tema de <seguridad nacional>”. 07 de abril, 2014, Honduras. Recuperado de http://www.elheraldo.hn/pais/571463-214/conflicto-en-elbajo-aguan-es-un-tema-de-seguridad-nacional

Fajardo, Byron José. “Diagnóstico situacional económico productivo del sector de palma africana en Honduras" (tesis de licenciatura). Universidad Zamorano, Honduras. 2006.

FAO. Faostat. 2017. Recuperado de http://www.fao.org/faostat/en/\#data/QC

FAO-OMS. "Joint FAO/who meeting on pesticide residues". Summary report. may, 2016. Recuperado de http://www.who.int/foodsafety/jmprsummary2016.pdf

Féliz, Mariano. Neoextractivismo, neodesarrollismo y proceso de acumulación de capital: ¿Superando el ciclo stop-and-go?, Argentina, 2003-2012. VII Jornadas de Sociología de la UNLP. La Plata, Argentina. 2012: 5-7. Recuperado de http://www.memoria.fahce.unlp. edu.ar/trab_eventos/ev.1887/ev.1887.pdf

Flores, José M. Honduras. El conflicto agrario del Bajo Aguán. El Socialista Centroamericano. 06 de abril, 2010. Recuperado de http://elsoca.org/index.php/component/content/ article?id=1247:honduras-el-conflicto-agrario-del-bajo-aguan

Gago, Verónica y Mezzadra, Sandro. "Para una crítica de las operaciones extractivas del capital". Nueva Sociedad, 255, 2015: 38-52.

García, Paola. “Tierra, palma africana y conflicto armado en el Bajo Atrato chocoano, Colombia. Una lectura desde el cambio en los órdenes de extracción". Estudios SocioJurídicos, 16(1), 2014: pp. 209-244.

GRAIN. Palma africana: las comunidades pagan el costo de un aceite "barato". 2016. Recuperado de https://www.grain.org/article/entries/5439-palma-africana-las-comunidades-paganlo costoso-de-un-aceite-barato

GREPALMA (Gremial de Palmicultores de Guatemala), 2016. La Palma en Guatemala en cifras. Recuperado de http://www.grepalma.org/en-cifras?o=4 
Gudynas, Eduardo. Extracciones, extractivismos y extrahecciones. Observatorio del Desarrollo, 18, 2013: 1-18.

Guerra-Borges, Alfredo. Política comercial norteamericana: la Iniciativa de la Cuenca del Caribe. Anuario de Estudios Centroamericanos, 11. 1985: 43-57.

Harvey, David. El "nuevo" imperialismo: acumulación por desposesión. Socialist register. CLACSO. 2004: 100-129. Recuperado de http://biblioteca.clacso.edu.ar/clacso/ se/20130702120830/harvey.pdf

Hernández, Oswaldo J. Desplazar para no ser desplazados: palma, narcos y campesino. Plaza Pública [Periodismo de profundidad]. 30 de septiembre, 2012. Recuperado de https:// www.plazapublica.com.gt/content/desplazar-para-no-ser-desplazados

Hurtado, Laura. Dinámicas agrarias y reproducción campesina en la globalización: el caso de Alta Verapaz, 1970-2007. Guatemala. F\&G Editores. 2008.

InsightCrime.org. Grupos de Poder en Peten: Territorio, politica y negocios. Guatemala. 2011. Recuperado de https://www.plazapublica.com.gt/sites/default/files/the-petenreport.pdf

Instituto Nacional de Estadística (INE). República de Guatemala: Encuesta Nacional Agropecuaria 2014. Instituto Nacional de Estadística, Guatemala. 2015. Recuperado de http://www.ine.gob.gt/sistema/uploads/2015/10/16/iQH6CPCSZUC1uOPe8fRZPen2qvS5DWsO.pdf

La Gaceta, Diario Oficial de la República de Honduras. Acuerdo Marco para la Competitividad de la Palma Africana y otras palmáceas. 13 de enero de 2006.

La Prensa. Asesinan en Tocoa al Presidente del Movimiento Campesino Muca. 18 de octubre, 2016. Honduras. Recuperado de http://www.laprensa.hn/sucesos/1009686-410/ asesinan-en-tocoa-al-presidente-del-movimiento-campesino-muca

Liberti, Stefano. Los nuevos amos de la tierra. México. Taurus. 2015.

Marx, Carlos. El Capital. Crítica de la Economía Política. México. Fondo de Cultura Económica. 1975.

Medina, Marel. "Hablemos de Honduras. Ensayo sobre el desarrollo humano de Honduras". 2007. Recuperado de http://www.angelfire.com $/ \mathrm{ca} 5 / \mathrm{mas} / \mathrm{mmb} / \mathrm{m} . h \mathrm{tml}$

Mingorría, Sara. "Violencia, silencio, miedo: el desvelo del conflicto de palma aceitera y caña de azúcar en el Valle del Polochic, Guatemala". Ecología Política, 51, 2016: pp. 73-78.

Movimiento Mundial por los Bosques Tropicales. “Expansión de las plantaciones de palma aceitera como política de Estado en Centroamérica". Boletín, 226. 2016. Recuperado de http://wrm.org.uy/es/files/2016/10/Boletin226_ESP-PDF-2.pdf

Observatorio para la Protección de los Defensores de Derechos Humanos. Honduras, criminalización en el Bajo Aguán: justicia a medias. Informe de Misión de observación Judicial. Honduras. COFADEH. 2016. Recuperado de https://www.fidh.org/IMG/pdf/criminalisation_obs_honduras_es_sept_2016_web_ok_2.pdf

Ocampo, Sebastián. Agroindustria y conflicto armado. El caso de la palma de aceite. Colombia Internacional, 70, 2009: 160-190.

OFRANEH. Honduras: WWF y la cooperación holandesa fomentan el mortal cultivo de palma africana. La haine.org. 14 de agosto de 2013. Recuperado de https://www.lahaine.org/ mundo.php/honduras-wwf-y-la-cooperacion-holandesa

Oil world-sinagap. "Serie histórica de precios". Fundación de Fomento de Exportaciones de Aceite de Palma y sus Derivados de Origen Nacional (FEDAPAL). 2017. Recuperado de http://www.fedapal.org/web2017/index.php/serie-historica-de-precios 
Orellana, Xiomara. "Palmeros exigen se controle venta de fruta". La Prensa. Honduras. 15 de agosto, 2013. Recuperado de http://www.laprensa.hn/content/view/full/95855

OXFAM. La pequeña agricultura en peligro. Expansión de los monocultivos, tierra, alimentos y medios de vida en América Latina. Informe de OXFAM 180. 23 de abril, 2014. Recuperado de https://issuu.com/0xfam/docs/bp180-smallholders-at-risk-land-foo_451b6e89ffd930

Petras, James. El programa de Reagan para la Cuenca del Caribe. Anuario de Estudios Centroamericanos, 8. 1982: 79-83.

Pocasangre, Henry. Contaminación del río La Pasión es un tema político. Prensa Libre. Guatemala. 21 de julio, 2015. Recuperado de http://www.prensalibre.com/guatemala/ comunitario/contaminacion-de-rio-la-pasion-es-un-tema-politico

Presidencia de la República. "Acuérdase Declarar el Estado de Sitio en todo el Departamento de Petén, durante treinta días". Decreto gubernativo 4-2011. Guatemala. 2011. Recuperado de http://www.cdhhg.org/pdf/Estado\%20de\%20Sitio\%20en\%20Peten\%5B1\%5D.pdf

Ramírez, Fernando, Bravo Virya y Herrera, Gustavo. Uso del herbicida glifosato en Costa Rica en el periodo 2007 a 2015. UNICIENCIA, 31(1). Enero-junio, 2017: 59-72. Recuperado de http://www.revistas.una.ac.cr/index.php/uniciencia

REPSA. Historia de la palma de aceite en Guatemala. (s. f.). Recuperado de http://repsa.com.gt/ historia-de-la-palma-de-aceite-en-guatemala/

REPSA. Plan de Sostenibilidad 2016-2017. 2017. Recuperado de http://repsa.com.gt/plan-desostenibilidad-2016-2017/

Robles Rivera, Francisco. Nuevos espacios de acumulación: modelo de ajuste estructural en el Salvador y Costa Rica (1980-1999). Revista de Ciencias Sociales, 2-3 (128-129), 2010: 97-117.

RSPO (Roundtable on Sustainable Palm Oil). Members. 2017. Recuperado de http://www.rspo. org/members/all

Roundtable on Sustainable Palm Oil (RSPO). Perfil de Agroaceite S. A. 2017. Recuperado de https://www.rspo.org/members/998/Agroaceite-S.A

Sánchez, Glenda y Obando, Walfredo. Contaminación en río La Pasión sigue impune. Prensa Libre. 17 de junio, 2016. Guatemala. Recuperado de http://www.prensalibre.com/guatemala/justicia/ministerio-de-ambiente-sanciono-a-repsa

Sassen, Saskia. Expulsiones. Brutalidad y complejidad en la economía global. Buenos Aires, Argentina: Katz, 2015.

Schumacher, Friedrich. Lo pequeño es hermoso. España: Ediciones Akal, 2011.

Solano, Luis. "Estudio del destino de la producción de caña de azúcar y palma africana y la situación de la producción y el mercado de agrocombustibles en Guatemala". actionaid. 2009. Recuperado de https://valledelpolochic.files.wordpress.com/2010/09/cac3b1aypalmaluissolano2011.pdf

Solano, Luis. ¿Hacia dónde va la producción de caña de azúcar y palma africana de Guatemala? actionaid. Serviprensa, S. A. 2011. Recuperado de http://www.actionaid.org/sites/files/ actionaid/version_resuminda_el_mercado_de_los_agrocombustibles_0.pdf

Solano, Luis. Palma africana y empresas se expanden aceleradamente a lo largo de la FTN. Enfoque, Análisis de situación, 7(36). 2015. Recuperado de http://www.albedrio.org/ htm/otrosdocs/comunicados/EnfoqueNo.36-PalmaafricanaFTN-2015.pdf

Svampa, Maristella. Consenso de los Commodities y lenguajes de valoración en América Latina. Nueva Sociedad, 244. 2013: 30-46.

Svampa, Maristella. Del cambio de época al fin de ciclo. Buenos Aires, Argentina. Edhasa. 2017. 
Techno Serve. Manual técnico de palma africana, San Pedro Sula, Cortés. 2009. Recuperado de http://www.coapalmaecara.com/files/05\%20Control\%20Fitosanitario.pdf

Vélez, Rodrigo. Denuncias, demandas y un Estado sordo. Plaza Pública, [periodismo de profundidad]. 22 de julio de 2015. Recuperado de http://www.plazapublica.com.gt/content/ denuncias-demandas-y-un-estado-sordo

Villatoro, Daniel. Repsa: el historial de una empresa investigada por ecocidio. Plaza Pública, [periodismo de profundidad]. 11 de febrero, 2016. Recuperado de https://www.plazapublica.com.gt/content/repsa-el-historial-de-una-empresa-investigada-por-ecocidio

Zepeda, Ricardo. Dinámicas agrarias y agendas de desarrollo en el valle del Polochic. Comité de Unidad Campesina. OXFAM. Guatemala. 2016. Recuperado de http://www.albedrio. org/htm/documentos/EstudioCUCconflictividadPolochic-2016.pdf

Zuckerman, Jocelyn. The Violent Costs of the Global Palm-Oil Boom. The New Yorker. December 10, 2016. Recuperado de http://www.newyorker.com/news/news-desk/ the-violent-costs-of-the-global-palm-oil-boom

Daniel Villafuerte Solís. Mexicano. Doctor en Ciencias Sociales por la Universidad Autónoma Metropolitana. Es investigador titular de tiempo completo del Centro de Estudios Superiores de México y Centroamérica de la Universidad de Ciencias y Artes de Chiapas, miembro del Sistema Nacional de Investigadores del CONACYT, nivel III. Es parte de la Red Internacional de Migración y Desarrollo. Sus investigaciones se han centrado en el tema de las integraciones entre México y Centroamérica, así como en los proyectos macrorregionales como el Proyecto Mesoamérica. Ha estudiado las migraciones transnacionales centroamericanas vinculadas a la seguridad fronteriza. Su publicación más reciente es el libro, en coautoría con María del Carmen García, Migración derechos humanos y desarrollo. Aproximaciones desde el sur de México y Centroamérica (2014).

Contacto: gasoda_2000@yahoo.com.mx

ORCID: 0000-0002-5866-4534 